\title{
El genocidio académico de la comparatística italiana
}

\author{
Entrevista a Alessandro Scarsella• \\ de la Università Ca' Foscari Venezia \\ Realizada y traducida por Adriana Crolla \\ Centro de Estudios Comparados, \\ Universidad Nacional del Litoral
}

AC: ¿Cuándo nace y dónde la Comparatística en Italia?

AS: Históricamente, la primera cátedra de Literatura Comparada es atribuida a Emilio Teza (1830-1912) en 1860 en la Universidad de Boloña. Teza nació en Venecia y fue bibliotecario en la Biblioteca Marciana, que conserva todavía una profusa bibliografía políglota.

Permítaseme un paréntesis autobiográfico: cuando en 1983, con jóvenes veinticinco años, entré como empleado regular en esta biblioteca de Venecia, habiendo ya dirigido mis intereses hacia la comparatística, vi en esto una señal favorable del destino. Por otra parte, por aquellos años las grandes bibliotecas eran sindicadas por Borges y Umberto Eco como lugares ideales de la literatura. Cuando, acompañado por Maria Kodama, Borges visitó la Marciana en su visita a Venecia en 1984, nos preguntó a mí y al recordado colega Giuliano Lenotti, cuál era la edición anotada de Dante que preferíamos. Respondimos que las de Sapegno y Momigliano. Pero él rebatió que su preferida era la segunda. ¡Dantistas de otra época y otros estilos!

Con el tiempo obtuve el Doctorado en Comparatística en la Universidad La Sapienza de Roma, con Elémire Zolla y por ende en 2005 opté por la Università Ca’Foscari de Venecia, donde Literaturas Comparadas fue, gracias a la presencia de Franco Meregalli (1913-2004), incluida en los estudios de Español e Iberística.

AC: ¿Quiénes son los primeros representantes de la disciplina? ¿Cuáles son los libros fundamentales?

AS: En Italia existía como precedente la Scienza nuova (1725) de Giambattista Vico, reconocido por Auerbach come el padre de la Comparatística. La influencia alemana es sin embargo radical, tanto en la escuela romántica de Francesco De

\footnotetext{
- Crítico literario nacido en Roma en 1958. Enseña Literaturas Comparadas en la Università Ca'Foscari de Venecia, después de haber trabajado 21 años, hasta 2005, en la Biblioteca Nazionale Marciana de esa misma ciudad. Es autor de artículos y ensayos sobre historia y teoría de la literatura, desde el humanismo hasta la época contemporánea. Miembro del comité científico de numerosas revistas literarias, ha publicado en el 2008 la antología Leggere la Costituzione, con escritos del Presidente de la República Italiana Giorgio Napolitano y del Sindaco de Venecia Massimo Cacciari. Ha colaborado con numerosas entradas de la Princeton Encyclopedia of Italian Literary Studies (Routledge, 2006). También del Dizionario Einaudi (2011) de la literatura norteamericana. Se ocupa además de bibliofilia, historia del libro, de la historieta y de graphic novel. Dirige el Laboratorio para el Estudio Literario de la Historieta.
} 
Sanctis, quien enseñó desde 1855 Literatura Comparada en Zurich, como sobre la positivista. Y es en ese ámbito que debemos buscar los primeros capolavori de la disciplina, desde Virgilio nel Medioevo (1872) de Domenico Comparetti y Le fonti dell'Orlando Furioso (1876) de Pio Rajna, a Il mito del paradiso terrestre (1892) de Arturo Graf. Sólo por citar los más importantes.

AC: ¿Cómo entra en la investigación comparada el fenómeno de la traducción?

AS: Desgraciadamente en medida poco relevante, si bien el italiano es ciertamente un pueblo de lectores de literatura extranjera en traducciones. Fenómeno del que se ha tomado conciencia al menos a partir del texto de Ruggero Bonghi, ¿Por qué la literatura italiana no es popular en Italia? (1856). Generalmente la traducción literaria es estudiada, salvo raras excepciones, por lingüistas y no por comparatistas. Quizás el error se debe a que la traductología y los numerosos manuales de traducción no gozan de buena fama entre los literatos. Es éste un campo donde se ve que hay mucho todavía por hacer y por dialogar.

AC: ¿Cuáles son los maestros italianos que debemos conocer en el extranjero para entender la comparatística italiana?

AS: Como vimos, la primera oleada de estudios comparados tuvo una impronta histórico-antropológica. En el período entre guerras y en la segunda mitad del S. $\mathrm{XX}$ se asistió en cambio, en el seno de la investigación sobre literaturas extranjeras, a un florecer de estudios de notable impacto comparatista: en el ámbito anglófono con Mario Praz, Agostino Lombardo y Sergio Perosa; en la eslava con Ettore Lo Gatto, Vittorio Strada y Angelo Maria Ripellino; en la hispanística Oreste Macrì y el ya citado Meregalli; en la germanística Ladislao Mittner y Furio Jesi; en la francesística Giovanni Macchia, Luigi De Nardis, Stefano Agosti, Francesco Orlando. A ellos deben sumarse en el ámbito de la italianística Gianfranco Contini, Cesare Segre, Ezio Raimondi. Del mito al texto, a la estructura lingüístico-retórica, a la recepción e interpretación, es en el interior de la expansión del horizonte propuesto por estos exponentes hacia otras literaturas y hacia nuevos modelos teóricos (franceses y rusos en particular) por donde debe buscar entenderse la matriz multiliteraria de la comparatística italiana contemporánea. Pero no se debe excluir el influjo positivo de grandes escritores-críticos muy atentos a las ciencias humanas y a la investigación como Pavese, Pasolini, Calvino y Zanzotto.

AC: ¿Cuáles son las tensiones, posiciones y proyecciones del comparatismo que se manifiestan en Italia actualmente?

AS: Quisiera destacar que la comparatística italiana fue desde hace algunos años dominada por personalidades convergentes pero demasiado fuertes para lograr coexistir, como Remo Ceserani (Guida allo studio della letteratura, Laterza 1999) y Armando Gnisci (Introduzione alla letteratura comparata, Mondadori 1999) y por ende condenados a la confrontación entre sí.

En algunos casos el hecho de haber superado obstáculos casi insuperables en sus carreras y el hecho de haber llegado a la cima demasiado tarde, los volvió intransi- 
gentes y excesivamente duros, muchas veces con sus mismos alumnos y potenciales aliados. El resultado fue el aislamiento de la materia y la consiguiente fuga hacia las literaturas nacionales, tanto sea la italiana como las extranjeras o las clásicas, por parte de aquellos que integraban la comparatística y que podrían haberla enseñado.

Y estamos ya en el nuevo siglo. Mientras desaparecía también la Sociología de la Literatura, que había ofrecido resultados notables y un talento crítico incomparable e internacionalmente reconocido, aunque no siempre bien comprendido como fue Romolo Runcini (1925-2014), profesor del Istituto Universitario Orientale de Nápoles durante más de 25 años. Los estudios de Runcini sobre la modernidad representan en el campo los resultados comparados de mayor espesor y de coherencia jamás superada en Italia. Tanto sea Illusione e paura e nel mondo borghese (Laterza 1968) como el póstumo Il romanzo industriale (Liguori 2012), compilado por Carlo Bordoni, su alumno y coautor de monografías nada más ni nada menos que con Zygmunt Bauman. Aunque no heredó la cátedra de Runcini, al haber sido despedido incomprensiblemente de la universidad.

AC: ¿Cuáles son las líneas y ámbitos de interés más desarrollados? Por ejemplo, en Argentina, los estudios comparados nacieron sobre todo de la mano de los profesores responsables de la enseñanza de las literaturas extranjeras y por necesidad de encontrar una metodología y un espacio propio en relación con las cátedras de literaturas en lenguas no española. En los Estados Unidos como rechazo a los departamentos de Inglés. ¿En Italia?

AS: Como ya dije mi experiencia individual con los ambientes de la Hispanística ha sido positiva dada la tradición de simpatía creada por Franco Meregalli. Generalmente con los hispanistas e hispanoamericanistas e iberísticos hay un buen diálogo, desde el momento que no piensan ser el centro del mundo y se interesan sobre todo por la existencia de los otros.

Para afrontar este aspecto de la cuestión es necesario tener en cuenta la tendencia al aislamiento moderno de la Comparatística, lo cual progresivamente se configura en Italia como un destino que hace a la doctrina comparatista como algo pasado de moda y por ende no curricular en las propuestas universitarias. Es difícil, por ejemplo, obtener una beca para un doctorado en comparatística. Ciertamente un motivo de crítica que ningún profesor ni ningún consorcio entre docentes e investigadores de la materia puede promover es la ausencia de cátedras de Literaturas Comparadas y de estudios de Literatura General en la escuela media y superior así como en los institutos de formación lingüística, donde en cambio está omnipresente la literatura nacional. La enseñanza universitaria en Italia está cada vez más ligada, y ya casi exclusivamente, a un tipo de formación tendiente a la enseñanza escolar. La posición de la literatura en las escuelas es exclusivamente nacionalista. $Y$ en este sentido la idea consensuada de hacer confluir los especialistas de comparatismo en el interior de maxi grupos para los concursos de Literatura Italiana podría tener una razón de ser y una lógica, si la correlacionamos con la primera Habilitación Científica Nacional. Un evento sin precedentes. 
AC: ¿Qué significó la Habilitación Científica Nacional para la Comparatística?

AS: Promulgada en 2012, la Habilitación Científica Nacional tuvo entre sus primeras intenciones la de evaluar el perfil de los aspirantes a la docencia para construir una especie de cuadro o tabla de todos los docentes universitarios a los cuales recurrir para el turn over. En realidad, el procedimiento ha dado lugar a una gran cantidad de recurrencias y un inmenso trabajo de escritos entre abogados y tribunales, estos últimos generalmente de acuerdo con las decisiones de la superioridad y con tendencia a ratificar los resultados de los concursos de una disciplina: la literatura, del todo ajena a sus competencias. En verdad, el fin inicial de la Habilitación era hacer justicia frente a las precedentes disparidades de tratamiento, estableciendo criterios claros, cualitativos y cuantitativos en la evaluación de un aspirante: las así llamadas mediane, que consisten en la detección de la presencia en el curriculum de un cierto número de publicaciones científicas de ensayos y artículos en revistas importantes, consideradas de clase A. Ahora bien, hemos dicho que los comparatistas más o menos jóvenes tenían que presentarse en el sector de la Literatura Italiana. En dicha comisión evaluaban los italianistas, dantistas fanáticos animados de una sed inmensa de ejercitar su juicio «final» y con la idea de establecer sumisiones, penas y castigos, en particular modo culpando al sector, considerado herético, de las literaturas extranjeras y de la teoría literaria. La primera decisión de esta comisión fue recusar la aplicación de las mediane concentrando en sus propias manos una discrecionalidad absoluta parangonable sólo a la filosofía iracunda de una purga stalinista. En sus juicios, que esperamos un día sean re publicados ya que fueron prudentemente quitados después de algunas semanas de visibilidad en el sitio público del Ministerio de la Universidad, se advierte un celo, un resentimiento y una perfidia, unido a un ensañamiento demasiado sádico para no resultar sospechoso, en especial hacia el anillo más débil de la cadena, o sea la comparatística, y hacia una minoría indefensa, los comparatistas, de los que se espera en efecto su desaparición material del organigrama académico.

Constituyéndose como el divide aguas final entre una orilla en la que, por lo que concierne a la literatura, en cuanto tal todavía existiría como idea en la universidad, y otra en la que se corre el riesgo de no continuar siendo, se sitúan las consabidas disparidades de tratamiento y promociones de hijos del arte, parientes, amigos y amigas. El hecho podría ser cínicamente considerado (no por mí, de hecho) por algunos como fisiológico al sistema, a condición sin embargo que se conservara en el procedimiento un pequeño margen de equidad y se mostrase un cierto pudor, no bajando el pulgar y concediendo algo también a los grupos minoritarios. Pero ni siquiera esto ocurrió.

Si hubiese sido necesaria una confirmación del genuino espíritu egocéntrico y destructivo de la completa consagración de los evaluadores italianistas, esto sería visible encendiendo la TV en el invierno de 2016, donde los telespectadores (y entre ellos los miserables comparatistas destruidos durante la Habilitación) habrían visto con incredulidad al "príncipe» de los italianistas y dantistas italianos, Marco Santagata, Presidente de la comisión habilitante, sentado como un mendigo que reclama popularidad en calidad de juez, en las pantallas del programa de preguntas y respuestas Rischiatutto. De la habilitación a un programa de divertimentos. Difícil comprender lo que puede empujar a un docente universitario que ha alcanzado 
el momento máximo de su carrera, y después de haber ejercido la responsabilidad antes mencionada, a mostrarse en la red televisiva estatal durante la cena de los italianos. Se hace necesaria una glosa: el pasaje de la habilitación al quiz define muy bien un carácter omnívoro y privado de tacto, estableciendo la confusión en todos los niveles, la ausencia de un mínimo buen sentido, una actitud autoritaria que parecerá absurda pero que los argentinos, con una memoria reciente de la dictadura, pueden ciertamente comprender. "Esta vez la piedad vence a la risa», tal como lo sugiere un verso de Eugenio Montale. Y existe también el famoso berretto a sonagli de Pirandello. País de la Commedia dell'Arte, Italia lo ha visto todo demasiado. Y para peor, en el momento de tomar conciencia de que la línea que divide lo grotesco de lo real es demasiado sutil, provoca el efecto de inducir a una sabiduría superior, resignadamente mixta, por supuesto. Por otra parte, las mayores figuras del pensamiento crítico italiano y aquellas más influyentes desde el extranjero, han obrado tradicionalmente por fuera de los marcos universitarios: Benedetto Croce, Antonio Gramsci, Giacomo Debenedetti. Y actualmente Alfonso Belardinelli (n. 1943) ${ }^{1}$

AC: Junto a estas tensiones, ¿cuáles son las posiciones del comparatismo en Italia hoy? ¿Existe una Asociación de Literatura Comparada o de Estudios Comparados? ¿Se han orga-nizado en modo corporativo con encuentros periódicos? ¿Se encuentran asociados a la ICLA (Asociación Internacional de Literatura Comparada)?

AS: Después del naufragio casi total de la disciplina, que me permití mostrar desde el punto de vista de las víctimas, se mira nuevamente a distancia y con justa razón, hacia la recuperación de la autonomía de la Comparatística y de la Teoría de la literatura como sector disciplinar separado de la Literatura Italiana, o sea, del lugar donde se consumó la traición - también del IV principio de la Constitución italiana que garantiza la justa oportunidad.

Es necesario mirar más lejos y pensar en prospectiva. En este sentido no ayuda la fragmentación de la realidad asociativa de los comparatistas y de los estudiosos de la literatura mundial. Históricamente y hasta hoy subsisten tres asociaciones: la SICL (Società Italiana di Comparatistica Letteraria) fundada en Florencia en 1980, donde predominan los francesistas, hispanistas, germanistas y estudiosos del tópico del viaje; la COMPALIT (Associazione per gli Studi di Teoria e Storia Comparata della Letteratura) desde 1993 con epicentro en Bolońa, afiliada a la ICLA y más completa en la representación de las variadas almas de la disciplina. Por último, en 2004 surgió en Milán la Consulta Universitaria di Critica letteraria e Letterature Comparate, con el fin más específico de reunir a los especialistas universitarios de la materia en una única asociación y bajo la tutela de su perfil.

Sólo de la acción conjunta de estas tres asociaciones podrán emerger la estrategia y la política necesaria para el renacimiento de la Comparatística italiana. No como objetivo con un fin en sí mismo sino unido a un renacimiento global de la cultura literaria. No sabemos si esto sucederá pero sabemos que los dos aspectos están relacionados. 
La publicación del reciente libro Universitaly (Laterza, 2016) por parte del presidente de la COMPALIT, Federico Bertoni, señala la obligación —expresándose por supuesto a título personal- de tomar posición seria de las cuestiones de fondo y de restablecer, al menos en nuestro microcosmo, la legalidad. Y por tanto poder esperar todavía la democracia. Siempre y cuando no sea demasiado tarde.

${ }^{1}$ Véase también su reciente ensayo Discorso sul romanzo moderno, Carocci, 2016.
}

\section{Crolla, Adriana}

